\title{
Influence of porosity on the analysis of sandwich plates FGM using of high order shear-deformation theory.
}

\author{
Slimane Merdaci \\ University of Sidi Bel Abbes, BP 89 Cité Ben M'bidi 22000 Sidi Bel Abbes, Algeria. \\ slimanem2016@gmail.com \\ Adda Hadj Mostefa \\ University of Rélizane, Institut des Sciences \& Technologie, Rélizane, Algeria. \\ badj9510@gmail.com
}

\begin{abstract}
In this article, the analytical solutions for static of bending analysis of functionally graded sandwich plates using four-variable high order shear-deformation theory is presented. During manufacture of these plates, defects such as porosities can appear. The objective of this paper is to develop a model to employ the new function for analysis the static of functionally graded sandwich plates. However, the material properties of the sandwich plate varies according to a power law P-FGM form through the thickness coordinate depending on the volume fraction of the constituent material. Equilibrium and stability equations are derived based on the present theory. The solution of the problem is derived by using Navier's technique. The influences of many sandwich plate parameters such of the variation and influences of porosity coefficient, aspect ratio, side-to-thickness ratio and exponent volume fraction will be investigated.
\end{abstract}

KEYWORDS. Sandwich plates; Bending; FGM; Porosity; High order theory

\section{OPEN ACCESS}

Citation: Merdaci, S., Hadj Mostefa, A., Influence of porosity on the analysis of sandwich plates FGM using of high order shear theory, Frattura ed Integrità Strutturale, 51 (2020) 199-214.

Received: 30.03.2019

Accepted: 24.11 .2019 Published: 01.01.2020

Copyright: (C2020 This is an open access article under the terms of the CC-BY 4.0, which permits unrestricted use, distribution, and reproduction in any medium, provided the original author and source are credited.

\section{INTRODUCTION}

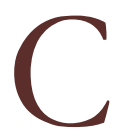
omposite materials are known as the modern materials which are composed of two or more different materials, to have the desired properties in specified applications. The lightweight composite materials known as fiber-matrix laminated composites have been used successfully in aircraft, automotive, marine industries and other engineering applications. However, the mismatch in mechanical properties across the interface of two different materials may cause large inter-laminar stresses.

Functionally graded materials (FGMs) are microscopically inhomogeneous spatial composite materials, typically composed of a ceramic-metal or ceramic-polymer pair of materials. Therefore, it is important to investigate the behaviors of engineering structures such as beams and plates made from FGMs when they are subjected to thermal loads for 
appropriate design. Frequently, FG plates are made from a mixture of two phases (metallic and ceramic) in which volume fraction of phases changing through the thickness.

To remedy such defects, functionally graded materials (FGMs), within which material properties vary continuously, have been proposed. The concept of FGM was proposed in 1984 by a group of materials scientists, in Sendai, Japan, for thermal barriers or heat shielding properties [1]. Functionally graded materials (FGMs) are recently developed advanced composite materials and are being widely used in various engineering appliances such as nuclear reactors and high speed spacecraft industries.

In recent years, these materials have found other applications in electrical appliances, energy transformation, biomedical engineering, optics, etc. [2]. However, in the manufacture of FGM, porosities may occur in the materials during the sintering process. This is due to the large difference in coagulation temperature between the components of the material [3]. Wattanasakulpong et al. [4] discussed the porosities that occur in lateral FGM samples made with a multistage sequential filtration technique. So, it is important to take under consideration the porosity effect when designing FG components under the effect of dynamic loadings.

Based on the open literature, it seems that many investigators have paid attention to the analysis of FGM structures with porosities. Most of these investigations are concerned with the vibration behavior of FG porous structures [5-19].

The objective of this article is to present the static of bending behavior of sandwich plates FGM having porosities. The sandwich plate may be either perfectly porous homogeneous or has a perfect homogeneity shape depending on the values of the volume fraction of voids (porosity) or of the graded factors. The sandwich plate is assumed isotropic at any point within the plate, with its Young's modulus varying across its thickness in accord with a power law P-FGM in terms of the volume fractions of the sandwich plate constituents while the Poisson's ratio remains constant. The present theory satisfies equilibrium conditions at the sandwich plate's top and bottom faces without using shear correction factors. A Navier's solution is used to obtain closed-form solutions for simply supported sandwich plates FG symmetrical. Several important aspects, i.e. aspect ratios, thickness ratios, exponent graded factor as well as porosity volume fraction, which affect deflections and stresses, are investigated. This paper explores the following elements:

- Formulation of the problem (Structural model and Displacement field and constitutive equations)

- Equilibrium equations

- Analytical solutions for FGM sandwich plate

- Numerical results and discussions

\section{FORMULATION OF THE PROBLEM}

\section{Structural model}

onsider a FG thick rectangular plate of length $\mathrm{a}$, width $\mathrm{b}$ and thickness $\mathrm{h}$ made of functionally graded material as shown in Fig.1 together with the adopted coordinate system. The material properties of the FG plate, such as Young's modulus E, are assumed to be function of the volume fraction of constituent materials.
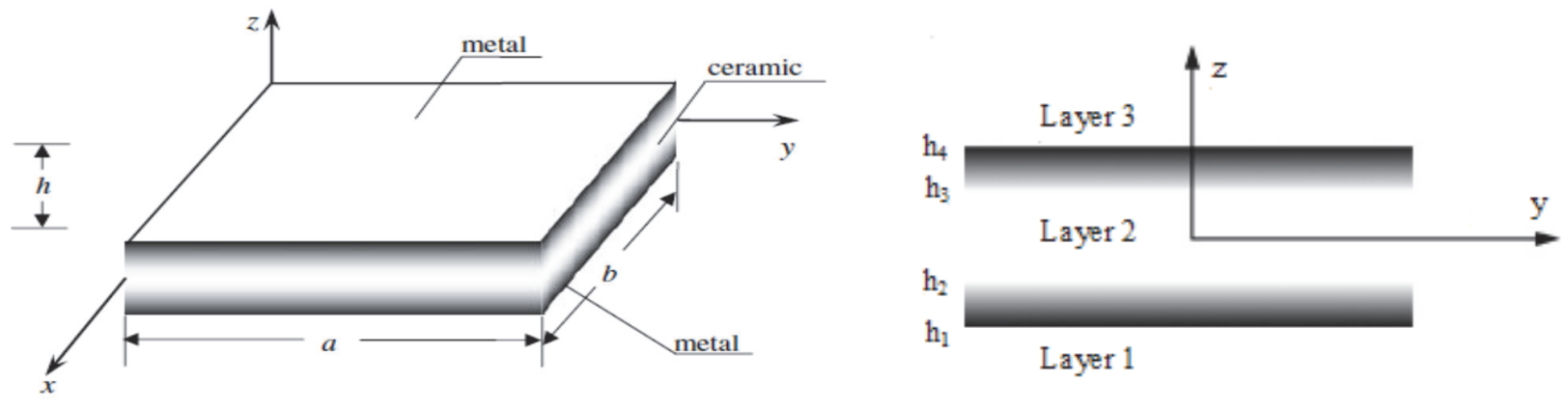

Figure 1: Geometry and coordinates of the porous sandwich plate FGM.

Let the sandwich plate FGM be subjected to a transverse load $q(x, y)$, and a rectangular Cartesian coordinate of $\mathrm{x}$ and $\mathrm{y}$ is introduced for the deformation analysis of the plate. The plate under study is bounded by the co-ordinate planes $0 \leq \mathrm{x} \leq \mathrm{a}$ and $0 \leq \mathrm{y} \leq \mathrm{b}$. The reference surface is the middle surface of the plate defined by $\mathrm{z}=0$, and $\mathrm{z}$ denotes the thickness coordinate measured from the un-deformed middle surface. 
Let the present plate is converted from lower to upper surfaces according to an exponential or polynomial laws. We will consider firstly a non-homogeneity material with a porosity volume function, $\alpha(0 \leq \alpha \leq 1)$. In such a way, the efficient material properties, as Young's modulus, can be expressed as:

$$
E=E_{0} e^{\left(\frac{1}{2}-\frac{z}{b}\right)^{P}-\frac{2 \alpha}{1-\alpha}}
$$

where $\mathrm{P}(\mathrm{P} \geq 0)$ represents a factor that points out the material variation through the thickness. Note that the plate is perfectly porous homogeneous when $\mathrm{k}$ equals zero and it gets the perfect homogeneity shape when $\mathrm{P}=\alpha=0$.

The functional relationship between $\mathrm{E}(\mathrm{z})$ for the ceramic and metal FGM plate is assumed to be is Ref. [30-31].

$$
E(z)=\left(E_{c}-E_{m}\right) V+E_{m}-\left(E_{c}+E_{m}\right) \frac{\alpha}{2} \quad \text { and } \quad V=\left(\frac{1}{2}+\frac{z}{b}\right)^{p}
$$

where $E_{c}$ and $E_{m}$ are the corresponding properties of the ceramic and metal, respectively, and " $P$ " is the volume fraction exponent which takes values greater than or equal to zero. The above power-law P-FGM assumption reflects a simple rule of mixtures used to obtain the effective properties of the ceramic-metal sandwich plate. The rule of mixtures applies only to the thickness direction. Note that the volume fraction of the metal is high near the bottom surface of the plate, and that of the ceramic is high near the top surface. Furthermore, Eqn. (2) indicates that the bottom surface of the plate $(z=$ $-\mathrm{h} / 2)$ is metal whereas the top surface $(\mathrm{z}=\mathrm{h} / 2)$ of the plate is ceramic.

In which $\mathrm{n}$ represents number of layers of sandwich plate and

$$
V^{(1)}=\left(\frac{z-b_{1}}{h_{2}-b_{1}}\right)^{P}, z \in\left[h_{1}, h_{2}\right] ; V^{(2)}=1, z \in\left[h_{2}, h_{3}\right] ; V^{(3)}=\left(\frac{z-b_{4}}{h_{3}-b_{4}}\right)^{P}, z \in\left[h_{3}, h_{4}\right]
$$

\begin{tabular}{cccc} 
Model & \multicolumn{1}{c}{ Theory } & Transverse shear function & $\begin{array}{c}\text { Unknown } \\
\text { variables }\end{array}$ \\
CPT & Classical plate theory & $f(z)=0$ & 3 \\
FSDPT & First-order shear deformation theory [26] & $f(z)=z$ & 5 \\
ESDPT & Exponential shear deformation plate theory $[28]$ & $f(z)=z \cdot e^{-2(z / h)^{2}}$ & 5 \\
SSDPT & Sinusoidal shear deformation plate theory $[27]$ & $f(z)=\frac{b}{\pi} \sin \left(\frac{\pi z}{h}\right)$ & 5 \\
HSDPT & Higher-order shear deformation theory[29] & $f(z)=z\left(1-\frac{4 z^{2}}{3 h^{2}}\right)$ & 5 \\
Present & Present higher-order shear deformation theory & $f(z)=z \cdot\left(\frac{1}{4}-\frac{5 z^{2}}{3 h^{2}}\right)$ & 4 \\
\hline
\end{tabular}

Table 1: Displacement models

\section{DISPLACEMENT FIELD AND CONSTITUTIVE EQUATIONS}

I

$\mathrm{n}$ the present analysis, the shear deformation plate theory is suitable for the displacements (Merdaci et al [20-25]): 


$$
\begin{gathered}
u(x, y, z)=u_{0}(x, y)-z \frac{\partial w_{b}}{\partial x}-f(z) \frac{\partial w_{s}}{\partial x} \\
v(x, y, z)=v_{0}(x, y)-z \frac{\partial w_{b}}{\partial y}-f(z) \frac{\partial w_{s}}{\partial y} \\
w(x, y, z)=w_{b}(x, y)+w_{s}(x, y)
\end{gathered}
$$

The number of unknown functions is only four, while five or more in the case of other shear deformation theories (Tab. 1).

The strains associated with the displacements in Eqn. (5) are

$$
\begin{gathered}
f^{\prime}(z)=\frac{d f(z)}{d z}=\frac{1}{4}-\frac{5 z^{2}}{b^{2}} \quad \text { and } \quad g(z)=1-f^{\prime}(z)=\frac{3}{4}-\frac{5 z^{2}}{b^{2}} \\
\varepsilon_{x}=\frac{\partial u_{0}}{\partial x}-z \frac{\partial^{2} w_{b}}{\partial x^{2}}-f(z) \frac{\partial^{2} w_{s}}{\partial x^{2}} \\
\varepsilon_{y}=\frac{\partial v_{0}}{\partial y}-z \frac{\partial^{2} w_{b}}{\partial y^{2}}-f(z) \frac{\partial^{2} w_{s}}{\partial y^{2}} \\
\gamma_{x y}=\left(\frac{\partial u_{0}}{\partial y}+\frac{\partial v_{0}}{\partial x}\right)-z\left(2 \frac{\partial^{2} w_{b}}{\partial x \partial y}\right)-f(z)\left(2 \frac{\partial^{2} w_{s}}{\partial x \partial y}\right) \\
\gamma_{y z}=g(z) \frac{\partial w_{s}}{\partial y} ; \quad \gamma_{x z}=g(z) \frac{\partial w_{s}}{\partial x} \text { and } \varepsilon_{z}=0
\end{gathered}
$$

For elastic and isotropic FGMs, the constitutive relations can be written as

$$
\left\{\begin{array}{c}
\sigma_{x} \\
\sigma_{y} \\
\tau_{x y}
\end{array}\right\}=\left[\begin{array}{ccc}
Q_{11} & Q_{12} & 0 \\
Q_{12} & Q_{22} & 0 \\
0 & 0 & Q_{66}
\end{array}\right]\left\{\begin{array}{l}
\varepsilon_{x} \\
\varepsilon_{y} \\
\gamma_{x y}
\end{array}\right\},\left\{\begin{array}{l}
\tau_{y z} \\
\tau_{z x}
\end{array}\right\}=\left[\begin{array}{cc}
Q_{44} & 0 \\
0 & Q_{55}
\end{array}\right]\left\{\begin{array}{l}
\gamma_{y z} \\
\gamma_{z x}
\end{array}\right\}
$$

where $\left(\sigma_{x}, \sigma_{y}, \tau_{x y}, \tau_{y z}, \tau_{y x}\right)$ and $\left(\varepsilon_{x}, \varepsilon_{y}, \gamma_{x y}, \gamma_{y z}, \gamma_{y x}\right)$ are the stress and strain components, respectively. Using the material properties defined in Eqn.(1), the stiffness coefficients, $Q_{i j}$, can be expressed as

$$
Q_{11}=Q_{22}=\frac{E(z)}{1-v^{2}}, Q_{11}=Q_{22}=\frac{E(z)}{1-v^{2}}, Q_{12}=\frac{v E(z)}{1-v^{2}}, Q_{44}=Q_{55}=Q_{66}=\frac{E(z)}{2(1+v)}
$$

\section{EQUILIBRIUM EQUATIONS}

7 he static equations can be obtained by using the principle of virtual displacements. It can be stated in its analytical form

$$
\int_{-b / 2}^{b / 2} \int_{\Omega}\left[\sigma_{x} \delta \varepsilon_{x}+\sigma_{y} \delta \varepsilon_{y}+\tau_{x y} \delta \gamma_{x y}+\tau_{y z} \delta \gamma_{y z}+\tau_{x z} \delta \gamma_{x z}\right] d \Omega d z-\int_{\Omega} q \delta W d \Omega=0
$$

where $\Omega$ is the top surface.

By substituting Eqns. (6) and (7) into Eqn. (9) and integrating through the thickness of the plate, Eqn. (14) can be rewritten 


$$
\begin{aligned}
& \int_{\Omega}\left[N_{x} \delta \varepsilon_{x}^{0}+N_{y} \delta \varepsilon_{y}^{0}+N_{x y} \delta \varepsilon_{x y}^{0}+M_{x}^{b} \delta k_{x}^{b}+M_{y}^{b} \delta k_{y}^{b}+M_{x y}^{b} \delta k_{x y}^{b}+M_{x}^{s} \delta k_{x}^{s}+\right. \\
& \left.+M_{y}^{s} \delta k_{y}^{s}+M_{x y}^{s} \delta k_{x y}^{s}+S_{y z}^{s} \delta \gamma_{y z}^{s}+S_{x z}^{s} \delta \gamma_{x z}^{s}\right] d \Omega-\int_{\Omega} q\left(\delta w_{b}+\delta w s\right) d \Omega=0
\end{aligned}
$$

where the stress resultants $\mathrm{N}, \mathrm{M}$, and $\mathrm{S}$ are defined by

$$
\left\{\begin{array}{lll}
N_{x}, & N_{y}, & N_{x y} \\
M_{x}^{b}, & M_{y}^{b}, & M_{x y}^{b} \\
M_{x}^{s}, & M_{y}^{s}, & M_{x y}^{s}
\end{array}\right\}=\sum \int_{-b / 2}^{b / 2}\left(\sigma_{x}, \sigma_{y}, \tau_{x y}\right)^{(n)}\left\{\begin{array}{c}
1 \\
z \\
f(z)
\end{array}\right\} d z,\left(S_{x z}^{s}, S_{y z}^{s}\right)=\sum \int_{-b / 2}^{b / 2}\left(\tau_{x z}, \tau_{y z}\right)^{(n)} g(z) d z .
$$

where $\mathrm{A}$ is the top surface, and the stress resultants $\mathrm{N}, \mathrm{M}$, and $\mathrm{s}$ are defined by:

$$
\begin{aligned}
& \left\{\begin{array}{c}
N \\
M^{b} \\
M^{s}
\end{array}\right\}=\left[\begin{array}{ccc}
A & B & B^{s} \\
A & D & D^{s} \\
B^{s} & D^{s} & H^{s}
\end{array}\right]\left\{\begin{array}{l}
\varepsilon \\
k^{b} \\
k^{s}
\end{array}\right\}, S=A^{s} \gamma, \\
& \left\{\begin{array}{l}
N_{x} \\
N_{y} \\
M_{x}^{b} \\
M_{y}^{b} \\
M_{x}^{s} \\
M_{y}^{s}
\end{array}\right\}=\left[\begin{array}{ccccc}
A_{11} & A_{12} & B_{11} B_{12} & B_{11}^{s} & B_{12}^{s} \\
A_{12} & A_{22} & B_{12} B_{22} & B_{12}^{s} & B_{22}^{s} \\
B_{11} & B_{12} & D_{11} D_{12} & D_{11}^{s} & D_{12}^{s} \\
B_{12} & B_{22} & D_{12} D_{22} & D_{12}^{s} & D_{22}^{s} \\
B_{11}^{s} & B_{12}^{s} & D_{11}^{s} D_{12}^{s} & H_{11}^{s} & H_{12}^{s} \\
B_{12}^{s} & B_{22}^{s} & D_{12}^{s} D_{22}^{s} & H_{12}^{s} & H_{22}^{s}
\end{array}\right] \times\left\{\begin{array}{l}
\varepsilon_{x}^{0} \\
\varepsilon_{y}^{0} \\
k_{x}^{b} \\
k_{y}^{b} \\
k_{x}^{s} \\
k_{y}^{s}
\end{array}\right\} \\
& \left\{\begin{array}{l}
N_{x y} \\
M_{x y}^{b} \\
M_{x y}^{s}
\end{array}\right\}=\left[\begin{array}{lll}
A_{11} & B_{66} & B_{66}^{s} \\
B_{66} & D_{66} & D_{66}^{s} \\
B_{66}^{s} & D_{66}^{s} & H_{66}^{s}
\end{array}\right]\left\{\begin{array}{l}
\gamma_{x y}^{0} \\
k_{x y}^{b} \\
k_{x y}^{s}
\end{array}\right\} \\
& \left\{\begin{array}{c}
S_{y z}^{s} \\
S_{x z}^{s}
\end{array}\right\}=\left[\begin{array}{cc}
A_{44}^{s} & 0 \\
0 & A_{55}^{s}
\end{array}\right]\left\{\begin{array}{l}
\gamma_{y z} \\
\gamma_{x z}
\end{array}\right\}
\end{aligned}
$$

where $A i j, B i j$, etc. are the plate stiffness defined by

$$
\begin{aligned}
& \left\{\begin{array}{llllll}
A_{11} & B_{11} & D_{11} & B_{11}^{s} & D_{11}^{s} & H_{11}^{s} \\
A_{12} & B_{12} & D_{12} & B_{12}^{s} & D_{12}^{s} & H_{12}^{s} \\
A_{66} & B_{66} & D_{66} & B_{66}^{s} & D_{66}^{s} & H_{66}^{s}
\end{array}\right\}=\sum_{n=1}^{3} \int_{b_{n}}^{b_{n+1}} Q_{11}^{(n)}\left(1, z, z^{2}, f(z), z f(z), f^{2}(z)\right)\left\{\begin{array}{c}
1 \\
v^{(n)} \\
\frac{1-v^{(n)}}{2}
\end{array}\right\} d z \\
& \left(A_{22}, B_{22}, D_{22}, B_{22}^{s}, D_{22}^{s}, H_{22}^{s}\right)=\left(A_{11}, B_{11}, D_{11}, B_{11}^{s}, D_{11}^{s}, H_{11}^{s}\right), Q_{11}^{(n)}=\frac{E(z)}{1-v^{2}} \\
& A_{44}^{s}=A_{55}^{s}=\sum_{n=1}^{3} \int_{b_{n}}^{b_{n+1}} \frac{E(z)}{2(1+v)}[g(z)]^{2} d z
\end{aligned}
$$


The governing equations of equilibrium can be derived from Eqn.(10) by integrating the displacement gradients by parts and setting the coefficients $\delta u, \delta v, \delta w_{b}$, and $\delta w_{s}$ zero separately. Thus, one can obtain the equilibrium equations associated with the present shear deformation theory,

$$
\begin{aligned}
& \delta u: \quad \frac{\partial N_{x}}{\partial x}+\frac{\partial N_{x y}}{\partial y}=0 \\
& \delta v: \quad \frac{\partial N_{x y}}{\partial x}+\frac{\partial N_{y}}{\partial y}=0 \\
& \delta w_{b}: \quad \frac{\partial^{2} M_{x}^{b}}{\partial x^{2}}+2 \frac{\partial^{2} M_{x y}^{b}}{\partial x \partial y}+\frac{\partial^{2} M_{y}^{b}}{\partial y^{2}}+q=0 \\
& \delta w_{s}: \quad \frac{\partial^{2} M_{x}^{s}}{\partial x^{2}}+2 \frac{\partial^{2} M_{x y}^{s}}{\partial x \partial y}+\frac{\partial^{2} M_{y}^{s}}{\partial y^{2}}+\frac{\partial S_{x z}^{s}}{\partial x}+\frac{\partial S_{y z}^{s}}{\partial y}+q=0
\end{aligned}
$$

\section{ANALYTICAL SOLUTIONS FOR FGM SANDWICH PLATE}

he following simply-supported boundary conditions are imposed at the side edges of the FG sandwich plate:

1

$$
\begin{aligned}
& v(0, y)=w_{b}(0, y)=w_{s}(0, y)=\frac{\partial w_{b}}{\partial y}(0, y)=\frac{\partial w_{s}}{\partial y}(0, y)=0 \\
& v(a, y)=w_{b}(a, y)=w_{s}(a, y)=\frac{\partial w_{b}}{\partial y}(a, y)=\frac{\partial w_{s}}{\partial y}(a, y)=0 \\
& N_{x}(0, y)=M_{x}^{b}(0, y)=M_{x}^{s}(0, y)=N_{x}(a, y)=M_{x}^{b}(a, y)=M_{x}^{s}(a, y)=0 \\
& u(x, 0)=w_{b}(x, 0)=w_{s}(x, 0)=\frac{\partial w_{b}}{\partial x}(x, 0)=\frac{\partial w_{s}}{\partial x}(x, 0)=0 \\
& u(x, b)=w_{b}(x, b)=w_{s}(x, b)=\frac{\partial w_{b}}{\partial x}(x, b)=\frac{\partial w_{s}}{\partial x}(x, b)=0 \\
& N_{y}(x, 0)=M_{y}^{b}(x, 0)=M_{y}^{s}(x, 0)=N_{y}(x, b)=M_{y}^{b}(x, b)=M_{y}^{s}(x, b)=0
\end{aligned}
$$

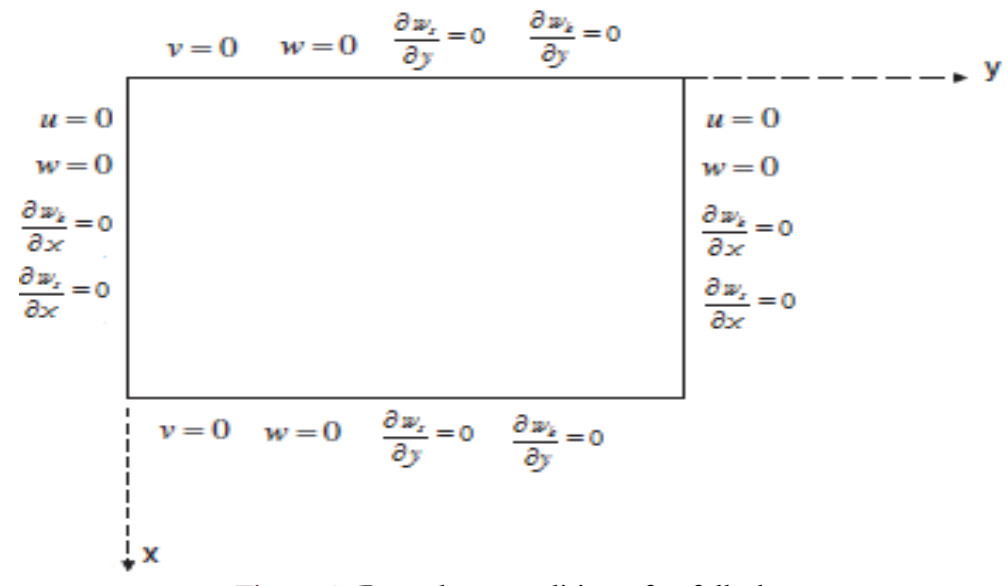

Figure 2: Boundary conditions for full plate. 
The external force according to Navier's solution can be expressed as

$$
q(x, y)=\sum_{m=1}^{\infty} \sum_{n=1}^{\infty} q_{m n} \sin (\lambda x) \sin (\mu y)
$$

where $\lambda=m \pi / a$ and $\mu=n \pi / b$, $\mathrm{m} »$ and $« \mathrm{n}$ »are mode numbers. For the case of a sinusoidally distributed load, we have

$$
m=n=1 \text { and } q_{11}=q_{0}
$$

where $\mathbf{q}_{0}$ represents the intensity of the load at the plate center.

Following the Navier solution procedure, we assume the following form of solution for $\left(\boldsymbol{u}, \boldsymbol{v}, \boldsymbol{w}_{\boldsymbol{b}}, \boldsymbol{w}_{\boldsymbol{s}}\right)$ that satisfies the boundary conditions

$$
\left\{\begin{array}{c}
u \\
v \\
w_{b} \\
w_{s}
\end{array}\right\}=\left\{\begin{array}{c}
U_{m n} \cos (\lambda x) \sin (\mu y) \\
V_{m n} \sin (\lambda x) \cos (\mu y) \\
W_{b m n} \sin (\lambda x) \sin (\mu y) \\
W_{s m n} \sin (\lambda x) \sin (\mu y)
\end{array}\right\},
$$

where $U_{m n}, V_{m n}, W_{b m n}$, and $W_{s m n}$ are arbitrary parameters. Eqn.(15) in combination with Eqn. (16) can be combined into a system of first order equations as:

$$
[K]\{\Delta\}=\{F\},
$$

where $\{\Delta\}$ and $\{F\}$ denotes the columns

$$
\{\Delta\}^{T}=\left\{U_{m n}, V_{m n}, W_{b m n}, W_{s m n}\right\}, \text { and }\{F\}^{T}=\left\{0,0,-q_{m n},-q_{m n}\right\}
$$

and

$$
[K]=\left[\begin{array}{llll}
a_{11} & a_{12} & a_{13} & a_{14} \\
a_{12} & a_{22} & a_{23} & a_{24} \\
a_{13} & a_{23} & a_{33} & a_{34} \\
a_{14} & a_{24} & a_{34} & a_{44}
\end{array}\right]
$$

The elements $a_{i j}=a_{j i}$ of the coefficient matrix $[\mathrm{K}]$. The elements of the symmetric matrix $[\mathrm{K}]$ presented in Eqn. (23) are given by

$$
\begin{aligned}
& a_{11}=-\left(A_{11} \lambda^{2}+A_{66} \mu^{2}\right) \\
& a_{12}=-\lambda \mu\left(A_{12}+A_{66}\right) \\
& a_{13}=\lambda\left[B_{11} \lambda^{2}+\left(B_{12}+2 B_{66}\right) \mu^{2}\right] \\
& a_{14}=\lambda\left[B_{11}^{s} \lambda^{2}+\left(B_{12}^{s}+2 B_{66}^{s}\right) \mu^{2}\right]
\end{aligned}
$$




$$
\begin{aligned}
& a_{22}=-\left(A_{66} \lambda^{2}+A_{22} \mu^{2}\right) \\
& a_{23}=\mu\left[\left(B_{12}+2 B_{66}\right) \lambda^{2}+B_{22} \mu^{2}\right] \\
& a_{24}=\mu\left[\left(B_{12}^{s}+2 B_{66}^{s}\right) \lambda^{2}+B_{22}^{s} \mu^{2}\right] \\
& a_{33}=-\left(D_{11} \lambda^{4}+2\left(D_{12}+2 D_{66}\right) \lambda^{2} \mu^{2}+D_{22} \mu^{4}\right) \\
& a_{34}=-\left(D_{11}^{s} \lambda^{4}+2\left(D_{12}^{s}+2 D_{66}^{s}\right) \lambda^{2} \mu^{2}+D_{22}^{s} \mu^{4}\right) \\
& a_{44}=-\left(H_{11}^{s} \lambda^{4}+2\left(H_{12}^{s}+2 H_{66}^{s}\right) \lambda^{2} \mu^{2}+H_{22}^{s} \mu^{4}+A_{55}^{s} \lambda^{2}+A_{44}^{s} \mu^{2}\right)
\end{aligned}
$$

\section{NUMERICAL RESULTS AND DISCUSSIONS}

$\mathrm{I}$ $\mathrm{n}$ this section, the present refined theory is applied to the bending analysis of sandwich plates FGM and. The Poisson's ratio is fixed at $\nu=0.3$, and comparisons are made with available solutions. Numerical case studies are used to verify the accuracy of the present analysis. The FG plate is taken to be made of aluminum and alumina with the following material properties:

- Metal (Aluminum, Al): $E m=70 \mathrm{GPa} ; \nu=0.3$.

- Ceramic (Alumina, $\mathrm{Al}_{2} \mathrm{O}_{3}$ ): $\mathrm{Ec}=380 \mathrm{GPa} ; \nu=0.3$.

The various non-dimensional parameters used are:

$$
\begin{aligned}
& \bar{w}=\frac{10 b E_{0}}{a^{2} q_{0}} w\left(\frac{a}{2}, \frac{b}{2}\right), \bar{\sigma}_{x}=\frac{10 b^{2}}{a^{2} q_{0}} \sigma_{x}\left(\frac{a}{2}, \frac{b}{2}, \frac{b}{2}\right), \bar{\sigma}_{y}=\frac{b}{a q_{0}} \sigma_{y}\left(\frac{a}{2}, \frac{b}{2}, \frac{b}{3}\right) \\
& \bar{\tau}_{x z}=\frac{b}{a q_{0}} \tau_{x z}\left(0, \frac{b}{2}, 0\right), \bar{\tau}_{y z}=\frac{b}{a q_{0}} \tau_{y z}\left(\frac{a}{2}, 0, \frac{b}{6}\right), \bar{\tau}_{x y}=\frac{b}{a q_{0}} \tau_{x y}\left(0,0,-\frac{b}{3}\right), \bar{z}=z / b
\end{aligned}
$$

The deflections and the dimensionless stresses of the square FG plate $(\mathrm{a} / \mathrm{h}=10)$ for different values of the volume fraction $P$ are presented including Tab.2. The present predictions (present refined theory) are compared with the CPT, first-order shear deformation theory (FSDPT) [26], higher-order (HSDPT) [29], Exponential (ESDPT) [28] and sinusoidal (SSDPT) [27]. It should be noted that all theory (CPT, FSDPT, ESDPT, HSDTT and SSDPT) were obtained on the basis of sinusoidal variation of both in-plane and transverse displacements across the thickness. It can be seen that SSDPT [27] presented sinusoidal theory with five unknowns. The present non-porous results $(\alpha=0)$ almost more accurate than those generated by other theories. Also, the present results are compared well with those of other solution.

The deflections dimensionless of the square plate $(a=b=1)$ symmetrical and unsymmetrical sandwich plate FGM $(a / h=$ 10) for different values of the volume fraction $P$ are presented in Fig.3. This figure shows that the displacement variation increases as $\mathrm{P}$ and $\alpha=0$ (no- porosity) increases, as we notice that the displacement variation of symmetrical FG and bigger than compared the symmetrical and unsymmetrical sandwich plate FGM.

In fig.4, the effect of the material index $\mathrm{P}$ on the adimensional displacement $\bar{w}$ of the perfect and imperfect FGM plate for values of the thickness ratio $(a / h=10)$ of the sandwich plate and different values of porosity coefficient using the present high order shear theory are illustrated in Fig.3. It should be noted that the dimensionless displacement increases with the increase of the value of the power law index for the perfect and imperfect sandwich plate FGM and that for the thickness ratio. Displacements are higher for metal plates while displacements are lower for all-ceramic plates $(\mathrm{P}=0)$. There is a rapid variation in displacements for the low values of the ratio a/h where the plate is considered thick. Exceeding this ratio of the material index $\mathrm{P}=2$, the displacements keep a more or less constant look and this for the 
different values of coefficient of the porosity. Fig. 4 Shows that the deflection increases as $\alpha$ and P increases. For greater values of $\alpha$, the differences in deflections may be more than double.

\begin{tabular}{|c|c|c|c|c|c|c|c|}
\hline Theories & $\mathrm{P}$ & $\bar{w}$ & $\bar{\sigma}_{x}$ & $\bar{\sigma}_{y}$ & $\bar{\tau}_{y z}$ & $\bar{\tau}_{x z}$ & $\bar{\tau}_{x y}$ \\
\hline СРТ & \multirow{6}{*}{ Ceramic } & 0.07722 & 1.97576 & 1.31718 & 0.15915 & 0.15915 & 0.70925 \\
\hline $\operatorname{FSDPT}(k=5 / 6)[26]$ & & 0.07722 & 1.97576 & 1.31718 & 0.15916 & 0.15916 & 0.70925 \\
\hline SSDPT[27] & & 0.07769 & 1.98392 & 1.31508 & 0.18995 & 0.20359 & 0.70812 \\
\hline ESDPT[28] & & 0.07770 & 1.98428 & 1.31502 & 0.19090 & 0.20740 & 0.70809 \\
\hline HSDPT[29] & & 0.07709 & 1.97408 & 1.31761 & 0.15111 & 0.14874 & 0.70948 \\
\hline Present & & 0.07791 & 1.99432 & 1.31236 & 0.21206 & 0.23857 & 0.70666 \\
\hline СРТ & \multirow{6}{*}{$\mathrm{P}=1$} & 0.19586 & 0.93765 & 1.54787 & 0.19570 & 0.26880 & 0.83347 \\
\hline $\operatorname{FSDPT}(k=5 / 0)[26]$ & & 0.19586 & 0.93765 & 1.54787 & 0.19570 & 0.26880 & 0.83347 \\
\hline SSDPT[27] & & 0.19610 & 0.94056 & 1.54745 & 0.20986 & 0.30894 & 0.83324 \\
\hline ESDPT[28] & & 0.19610 & 0.94070 & 1.54751 & 0.20974 & 0.31299 & 0.83327 \\
\hline HSDPT[29] & & 0.19577 & 0.93697 & 1.54798 & 0.19104 & 0.25827 & 0.83353 \\
\hline Present & & 0.19609 & 0.94370 & 1.54687 & 0.21637 & 0.33433 & 0.83293 \\
\hline СРТ & \multirow{6}{*}{$\mathrm{P}=2$} & 0.28509 & 1.36934 & 1.36210 & 0.19078 & 0.34892 & 0.73344 \\
\hline $\operatorname{FSDPT}(k=5 / 0)[26]$ & & 0.28509 & 1.36934 & 1.36210 & 0.19078 & 0.34892 & 0.73344 \\
\hline SSDPT[27] & & 0.28514 & 1.37294 & 1.36172 & 0.19822 & 0.38854 & 0.73324 \\
\hline ESDPT[28] & & 0.28511 & 1.37311 & 1.36177 & 0.19739 & 0.39220 & 0.73326 \\
\hline HSDPT[29] & & 0.28502 & 1.36847 & 1.36220 & 0.18759 & 0.33768 & 0.73349 \\
\hline Present & & 0.28490 & 1.37662 & 1.36123 & 0.19888 & 0.40919 & 0.73297 \\
\hline $\mathrm{CPT}$ & \multirow{6}{*}{$\mathrm{P}=3$} & 0.336721 & 1.61758 & 1.25527 & 0.17464 & 0.41003 & 0.67591 \\
\hline $\operatorname{FSDPT}(k=5 / 6)[26]$ & & 0.33672 & 1.61758 & 1.25527 & 0.17464 & 0.41003 & 0.67591 \\
\hline SSDPT[27] & & 0.33666 & 1.62155 & 1.25475 & 0.17975 & 0.45234 & 0.67564 \\
\hline ESDPT[28] & & 0.33660 & 1.62171 & 1.25478 & 0.17864 & 0.45568 & 0.67565 \\
\hline HSDPT[29] & & 0.33667 & 1.61661 & 1.25541 & 0.17195 & 0.39739 & 0.67599 \\
\hline Present & & 0.33624 & 1.62552 & 1.25415 & 0.17844 & 0.47133 & 0.67531 \\
\hline $\mathrm{CPT}$ & \multirow{6}{*}{$\mathrm{P}=4$} & 0.36538 & 1.75385 & 1.23316 & 0.15823 & 0.45817 & 0.66401 \\
\hline $\operatorname{FSDPT}(k=5 / 6)[26]$ & & 0.36538 & 1.75385 & 1.23316 & 0.15823 & 0.45817 & 0.66401 \\
\hline SSDPT[27] & & 0.36527 & 1.75807 & 1.23249 & 0.16289 & 0.50554 & 0.66365 \\
\hline ESDPT[28] & & 0.36519 & 1.75823 & 1.23251 & 0.16173 & 0.50878 & 0.66366 \\
\hline HSDPT[29] & & 0.36532 & 1.75281 & 1.23333 & 0.15568 & 0.44369 & 0.66410 \\
\hline Present & & 0.36474 & 1.76229 & 1.23174 & 0.16129 & 0.52541 & 0.66325 \\
\hline $\mathrm{CPT}$ & \multirow{6}{*}{$\mathrm{P}=5$} & 0.3818576 & 1.83097 & 1.24289 & 0.14497 & 0.49709 & 0.66925 \\
\hline $\operatorname{FSDPT}(k=5 / 6)[26]$ & & 0.38186 & 1.83097 & 1.24289 & 0.14497 & 0.49709 & 0.66925 \\
\hline SSDPT[27] & & 0.38175 & 1.83541 & 1.24208 & 0.14989 & 0.55087 & 0.66881 \\
\hline ESDPT[28] & & 0.38166 & 1.83557 & 1.24209 & 0.14877 & 0.55423 & 0.66882 \\
\hline HSDPT[29] & & 0.38177 & 1.82984 & 1.24307 & 0.14228 & 0.48020 & 0.66935 \\
\hline Present & & 0.38116 & 1.83989 & 1.24120 & 0.14864 & 0.57337 & 0.66834 \\
\hline СРT & \multirow{6}{*}{ Metal } & 0.41919 & 1.97576 & 1.31718 & 0.15916 & 0.15916 & 0.70925 \\
\hline $\operatorname{FSDPT}(k=5 / 0)[26]$ & & 0.41919 & 1.97576 & 1.31718 & 0.15916 & 0.15916 & 0.70925 \\
\hline SSDPT[27] & & 0.42172 & 1.98392 & 1.31508 & 0.18995 & 0.20359 & 0.70812 \\
\hline ESDPT[28] & & 0.42180 & 1.98428 & 1.31502 & 0.19090 & 0.20740 & 0.70809 \\
\hline HSDPT[29] & & 0.41847 & 1.97408 & 1.31761 & 0.15111 & 0.14874 & 0.70948 \\
\hline Present & & 0.42294 & 1.99432 & 1.31236 & 0.21206 & 0.23857 & 0.70666 \\
\hline
\end{tabular}

Table. 2: Comparative study of deflections and stress non-dimensional of sandwich plate FGM for different volume fraction value. 


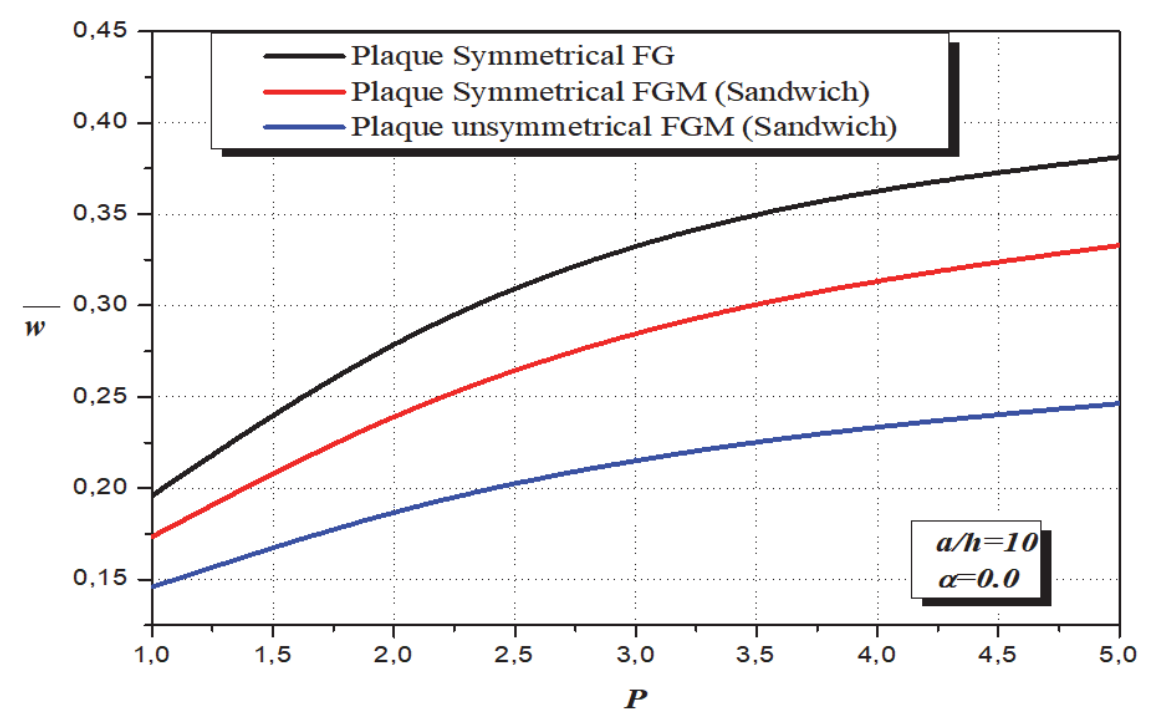

Figure 3: Displacement variation as a function of the power index P and the porosity factor $\alpha=0$ of sandwich plate FGM.

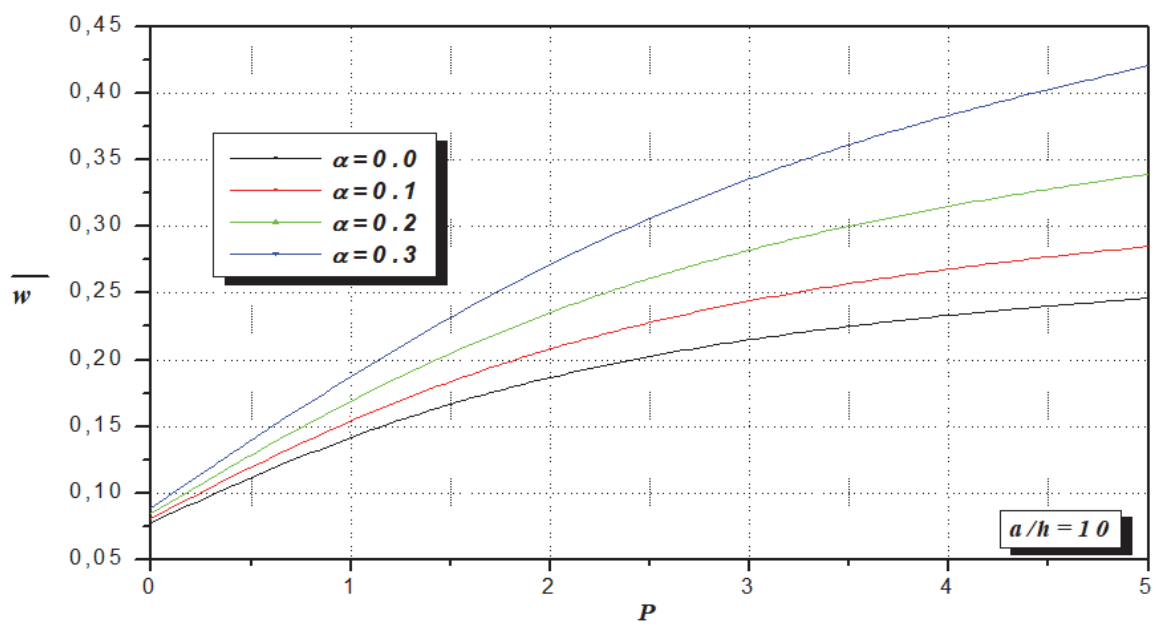

Figure 4: Displacement variation $\bar{w}$ as a function of the power index $\mathrm{P}$ and the different porosity factor $\alpha$ of sandwich plate FGM

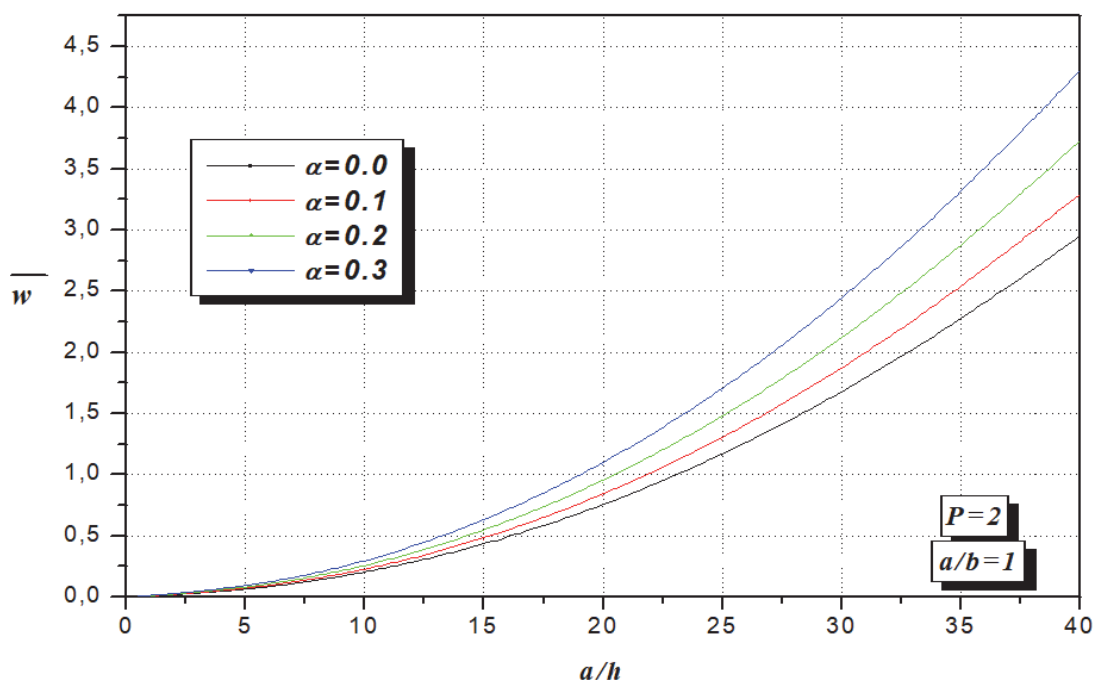

Figure 5: Dimensionless displacement variation as a function of the thickness ratio a/h for the different values of porosity coefficient for plate sandwich FGM. 


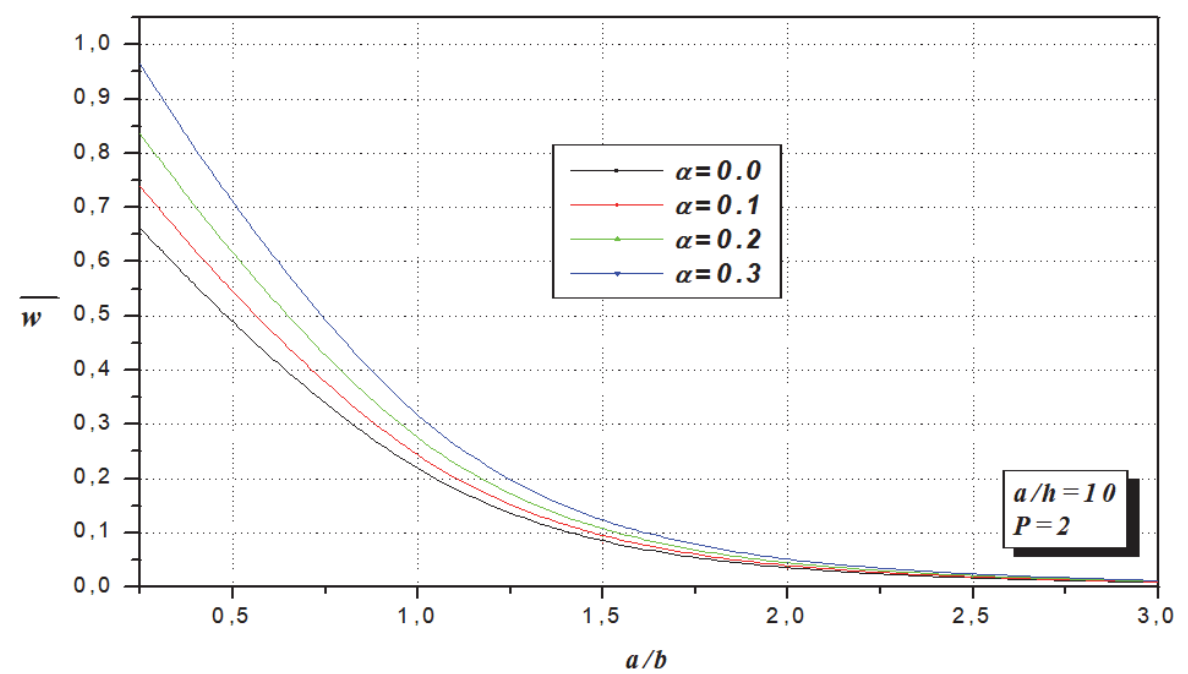

Figure 6: Variation of dimensional displacement as a function of the geometric ratio a/b for the different values of porosity coefficient for plate sandwich FGM.

Fig.5, shows the increase in dimensionless displacements, which is explained by the influence of material stiffness, ie an increase in the value of the power index $\mathrm{P}$, leads to a decrease in the modulus of elasticity of the material plate. In other words, the plates become flexible as the power law index increases, and thus increase the displacement values. In addition, the porosity $(\alpha)$ leads to a remarkable increase in plate displacement. An increase in the ratio (a/h) leads to an increase in adimensional displacements. We can also say that the thickness ratio $(\mathrm{a} / \mathrm{h})$ has a considerable effect on dimensionless displacement. In fig.6, we study adimensional displacement variation as a function of the geometric ratio (a/b) for the different values of porosity coefficient with a ratio of equal thickness $(\mathrm{a} / \mathrm{h}=10)$ and a material index $\mathrm{P}=2$ for this plate sandwich FGM. Decreasing of said ratio makes lowering of displacement.

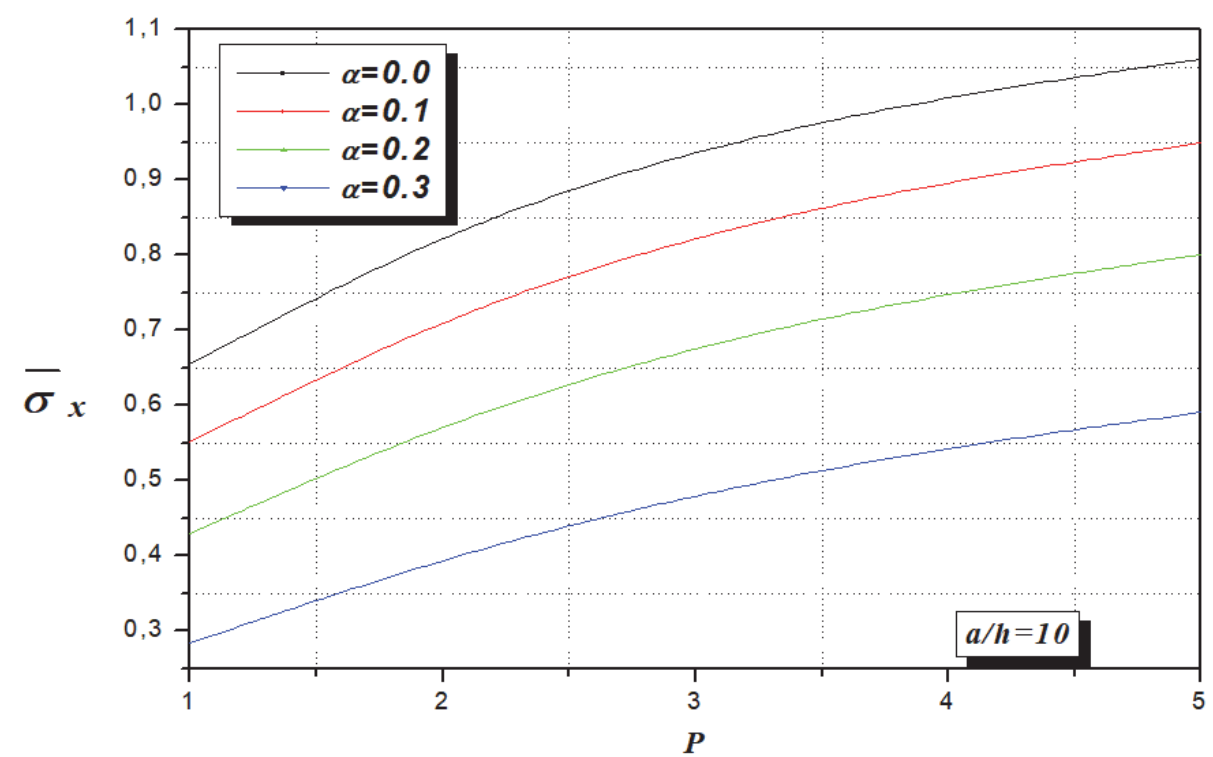

Figure 7: Variation of stress non-dimensional $\bar{\sigma}_{x}$ as a function of the power index $\mathrm{P}$ and the different porosity factor $\alpha$ of sandwich plate FGM.

Now, the results for the FG thick $(a / h=10)$, square $(b=a)$ sandwich plates are presented for various values of the porosity $(\alpha)$ and the graded P parameters. Fig. 7 shows the variation of stress $\bar{\sigma}_{x}$ of the sandwich plate embedding an FG 
core for different exponential factor $\mathrm{P}$. this figure shows that the stress $\bar{\sigma}_{x}$ increases as $\mathrm{P}$ and $\alpha=0$ (noporosity)increases, as we notice that the stress will have a decrease in the presence of porosity factor $\alpha \neq 0$. In fig. 8 shows the Variation of stress non-dimensional $\bar{\sigma}_{y}$ of the sandwich plate embedding an FG core for different exponential factor $\mathrm{P}$ and for different porosity factor $\alpha(0.1,0.2$ and 0.3$)$ for the stress non-dimensional $\bar{\sigma}_{y}$. It should be noted that the stress dimensionless increases with the increase of the value of the power law index $\mathrm{P}$ and the different porosity factor $\alpha$ for the perfect and imperfect FGM plate sandwich and that for the thickness ratios $(\mathrm{a} / \mathrm{h}=10)$.

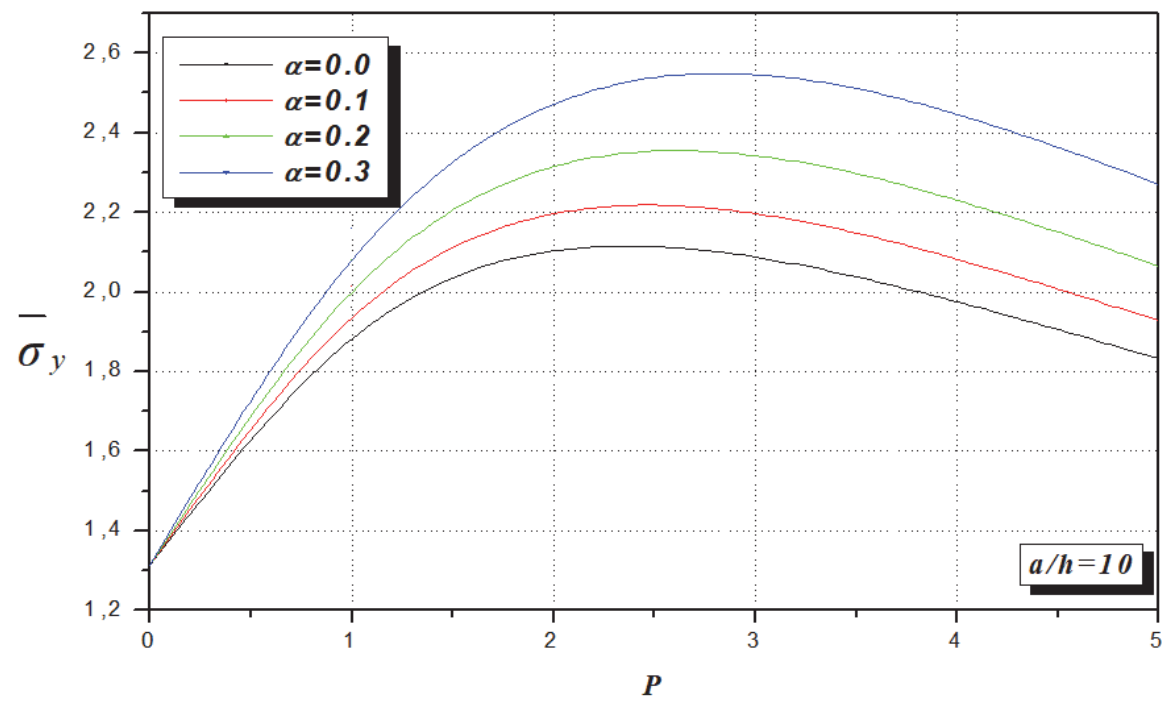

Figure 8: Variation of stress non-dimensional as a function of the power index $\mathrm{P}$ and the different porosity factor $\alpha$ of sandwich plate FGM.

In Figs.9, 10 and 11, contains the variation of the transverse shear stress across the exponent of the volume fraction $\mathrm{P}$ for the sandwich plate FGM. The effect of the porosity of the FGM plate was taken into account by means of the introduction of the coefficient $(\alpha)$. Four values are therefore retained $(\alpha=0,0.1,0.2$ and 0.3$)$. for Figs.6 the transverse shear stress non-dimensional $\bar{\tau}_{x y}$ has an increase with respect to power index $\mathrm{P}=1$ afterwards one observes a decrease of these transverse shear stress according to the decrease of factor of porosity which has an influence this plate sandwich. In figs.10 and 11 it can be seen that the increase in the index of porosity $(\alpha)$ leads to an increase in stresses. This can be justified by the fact that the porosity reduces the rigidity of the plate. The stresses are tensile above the median plane and compression below the median plane. It is important to observe that the maximum stress depends on the value of the exponent of the volume fraction P.

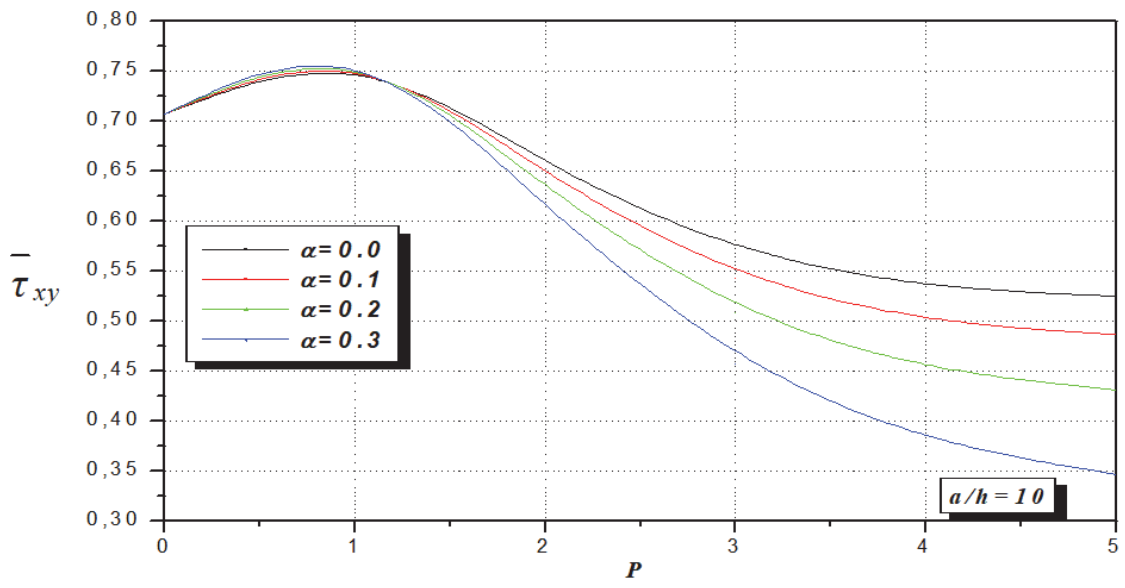

Figure 9: Variation of tangential stress non-dimensional $\bar{\tau}_{x y}$ as a function of the power index $\mathrm{P}$ and the different porosity factor $\alpha$ of sandwich plate FGM. 


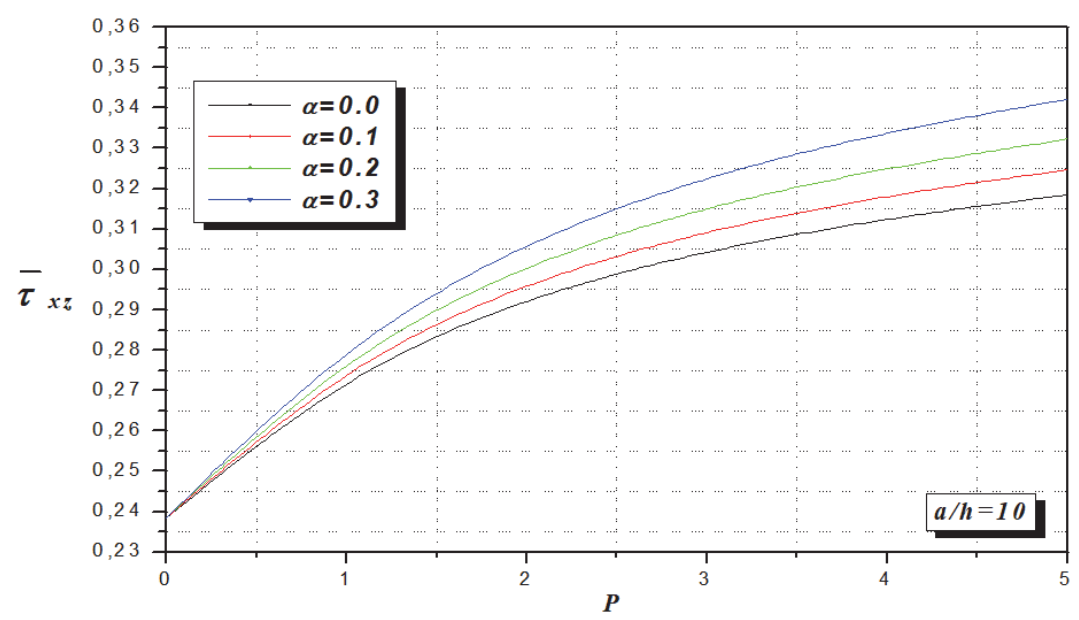

Figure 10: Variation of tangential stress non-dimensional $\bar{\tau}_{x z}$ as a function of the power index P and the different porosity factor $\alpha$ of sandwich plate FGM.

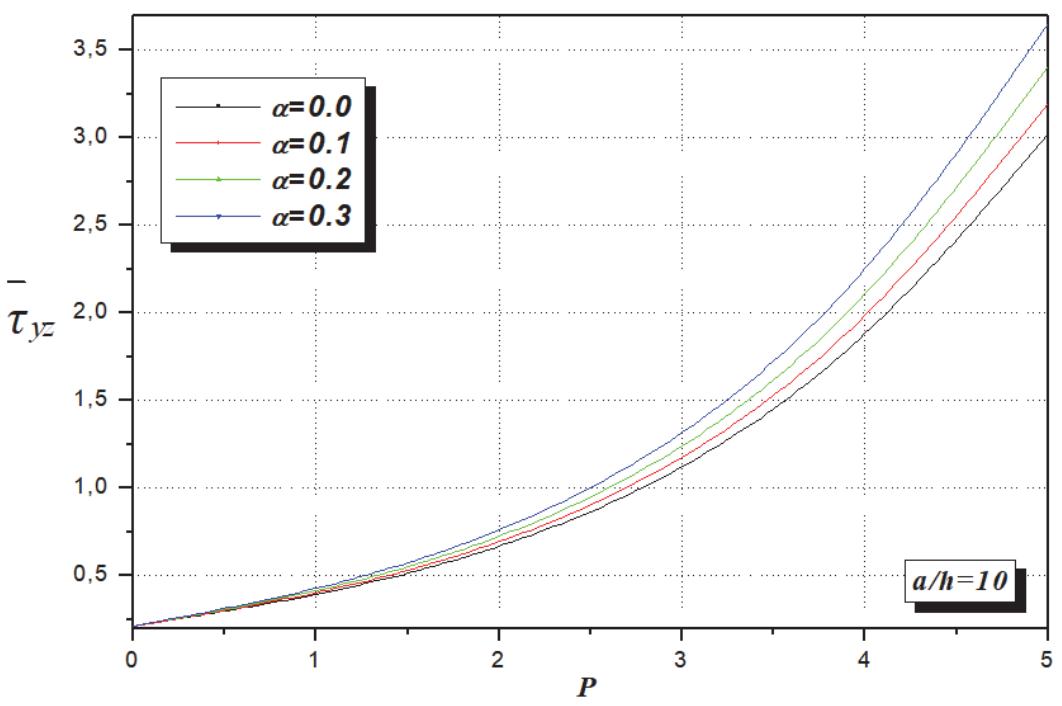

Figure 11: Variation of tangential stress non-dimensional $\bar{\tau}_{y z}$ as a function of the power index P and the different porosity factor $\alpha$ of sandwich plate FGM.

\section{CONCLUSION}

A new simple for four-variable theory of high order shear and normal deformation theory is developed for functionally graded sandwich plates FGM. The principle of virtual displacements is used to derive the governing equations and boundary conditions. Then, analytical solutions for functionally graded porous square sandwich plates are presented. The inclusions of porosity parameters and exponent of the volume fraction $P$ are investigated. The effects of various parameters, such as thickness ratio, gradient index, and volume fraction of porosity on the flexion of FGM ceramic-metal sandwich plates symmetrical are all discussed. Many validations examples are reported and numerical results of the present high order shear and normal deformation theory is accurate in predicting the static of bending response of non-porous sandwich plates. In addition, the present theory gave control results that can be used to evaluate various plate theories, and also to compare with the results obtained by another solution (CPT, FSDPT, ESDPT, SSDPT and HSDPT). From this work, it can be said that the present and simple theory for the resolution of the mechanical behavior of FGM plates sandwich with porosity that presses manufacturing defects. 


\section{REFERENCES}

[1] Koizumi, M. (1997). FGM activities in Japan[]]. Composites;28(1-2): pp.1-4. DOI: 10.1016/S1359-8368(96)00016-9

[2] Suresh, S., Mortensen, A. (1998). Fundamental of functionally graded materials. London: Maney. DOI: 10.1016/j.compscitech.2007.08.029

[3] Zhu, J., Lai, Z., Yin, Z., Jeon, J., Lee, S. (2001). Fabrication of ZrO2-NiCr functionally graded material by powder metallurgy. Mater Chem Phys 68, pp.130-5. DOI: 10.1016/j.msea.2009.01.066

[4] Wattanasakulpong, N., Prusty, B.G., Kelly, D.W., Hoffman, M. (2012). Free vibration analysis of layered functionally graded beams with experimental validation 36, pp.182-90. DOI:10.1016/j.matdes.2011.10.049

[5] Rezaei, A.S., and Saidi, A.R. (2015). Exact solution for free vibration of thick rectangular plates made of porous materials, Compos. Struct. 134, pp.1051-1060. DOI: 10.1016/j.compstruct.2015.08.125

[6] Behravan Rad, A., Shariyat, M. (2015). Three-dimensional magneto-elastic analysis of asymmetric variable thickness porous FGM circular plates with non-uniform tractions and Kerr elastic foundations, Compos. Struct. 125, pp.558574. DOI: 10.1016/j.compstruct.2015.02.049

[7] Rezaei, A.S., and Saidi, A.R.. (2016). Application of Carrera unified formulation to study the effect of porosity on natural frequencies of thick porous-cellular plates, Composites, Part B, Eng. 91, pp.361-370. DOI: 10.1016/j.compositesb.2015.12.050

[8] Chen, D., Yang, J., Kitipornchai, S. (2016). Free and forced vibrations of shear deformable functionally graded porous beams, Int. J. Mech. Sci. 108-109, pp.14-22. DOI: 10.1016/j.ijmecsci.2016.01.025

[9] Chen, D., Kitipornchai, S., Yang, J. (2016). Nonlinear free vibration of shear deformable sandwich beam with a functionally graded porous core, Thin-Walled Struct. 107, pp.39-48. DOI: 10.1016/j.tws.2016.05.025

[10] Ebrahimi, F., Jafari, A., Barati, M.R. (2017). Vibration analysis of magneto-electro-elastic heterogeneous porous material plates resting on elastic foundations, Thin-Walled Struct. 119, pp.33-46. DOI:10.1016/j.tws.2017.04.002

[11] Rezaei, A.S., Saidi, A.R., Abrishamdari, M., Pour Mohammadi, M.H. (2017). Natural frequencies of functionally graded plates with porosities via a simple four variable plate theory: an analytical approach, Thin-Walled Struct. 120, pp. 366-377. DOI: 10.1016/j.tws.2017.08.003.

[12] Rezaei, A.S., and Saidi, A.R. (2017). On the effect of coupled solid-fluid deformation on natural frequencies of fluid saturated porous plates, Eur. J. Mech. A, Solids 63, pp. 99-109. DOI:10.1016/j.euromechsol.2016.12.006.

[13] Lhoucine, B., Khalid, E., and Rhali, B. (2017). Thermal behavior analysis at large free vibration amplitudes of thin annular FGM plates with porosities, Proc. Eng. 199, pp.528-533. DOI: 10.1016/j.proeng.2017.09.148.

[14] Al Rjoub, Y.S., and Hamad, A.G. (2017). Free vibration of functionally Euler-Bernoulli and Timoshenko graded porous beams using the transfer matrix method, KSCE J. Civ. Eng. 21(3), pp.792-806.

DOI:10.1007/s12205-016-0149-6

[15] Ghorbanpour Arani, A., Khani, M., and Khoddami Maraghi, Z. (2017). Dynamic analysis of a rectangular porous plate resting on an elastic foundation using high-order shear deformation theory, J. Vib. Control. 24(3), pp.1-16. DOI: $10.1177 / 1077546317709388$.

[16] Chen, D., Kitipornchai, S., and Yang, J. (2018). Dynamic response and energy absorption of functionally graded porous structures, Mater. Des. 140, pp.473-487. DOI: 10.1016/j.matdes.2017.12.019.

[17] Barati, M.R. (2018).A general nonlocal stress-strain gradient theory for forced vibration analysis of heterogeneous porous nanoplates, Eur. J. Mech. A, Solids 67, pp.215-230. DOI: 10.1016/j.euromechsol.2017.09.001.

[18] Barati, M.R. (2018).Vibration analysis of porous FG nanoshells with even and uneven porosity distributions using nonlocal strain gradient elasticity, Acta Mech. 229, pp.1183-1196. DOI:10.1007/s00707-017-2032-z.

[19] Barati, M.R., and Shahverdi, H. (2018). Nonlinear vibration of nonlocal four-variable graded plates with porosities implementing homotopy perturbation and Hamil-tonian methods, Acta Mech. 229, pp. 343-362.

DOI: $10.1007 / \mathrm{s} 00707-017-1952-y$

[20] Merdaci, S., Tounsi, A., Houari, M.S.A., Mechab, I., Hebali, H., and Benyoucef, S. (2011). Two new refined shear displacement models for functionally graded sandwich plates. Arch Appl Mech, 81, 1507e22. DOI: $10.1007 / \mathrm{s} 00419-010-0497-5$

[21] Merdaci, S., Tounsi, A., Bakora, A. (2016). “ A novel four variable refined plate theory for laminated composite plates”; An International Journal Steel \& Composite Structures. 22(4), pp.713-732.

DOI: $10.12989 /$ scs.2016.22.4.713

[22] Merdaci, S. (2017). "Study and Comparison of Different Plate Theory"; International Journal of Engineering Research And Advanced Technology (IJERAT); 3(8), pp.49-59. DOI: 10.7324/IJERAT.3130. 
[23] Hadj Mostefa, A., Merdaci, S., and Mahmoudi, N. (2018). An Overview of Functionally Graded Materials «FGM», Proceedings of the Third International Symposium on Materials and Sustainable Development, pp.267-278. DOI:10.1007/978-3-319-89707-3.

[24] Merdaci, S. (2018). Analysis of Bending of Ceramic-Metal Functionally Graded Plates with Porosities Using of High Order Shear Theory, Advanced Engineering Forum, 30, pp.54-70. DOI: 10.4028/www.scientific.net/AEF.30.54.

[25] Merdaci, S., and Belghoul, H. (2019). High Order Shear Theory for Static Analysis Functionally Graded Plates with Porosities, Comptes rendus Mecanique, 347(3), pp.207-217. DOI: 10.1016/j.crme.2019.01.001.

[26] Timoshenko, P. and Gere, J.M. (1972). Mechanics of Materials. New York: D.Van Nostrand Company. https://www.worldcat.org/title/mechanics-of-materials/oclc/251209

[27] Karama, M., Afaq, K.S., and Mistou, S. (2003). Mechanical behaviour of laminated composite beam by the new multilayered laminated composite structures model with transverse shear stress continuity, Int. J. Solids Structures; 40 (6), pp.1525-1546. DOI: 10.1016/S0020-7683(02)00647-9

[28] Touratier, M. (1991). An efficient standard plate theory. Engng Sci, 29(8), pp. 901-916. DOI: $10.1016 / 0020-7225(91) 90165-Y$.

[29] Reddy, J.N. (1984). Asimple higher-order theory for laminated composite plates. Trans. ASME J. Appl. Mech. 51, pp.745-752. DOI:10.1115/1.3167719.

[30] Praveen,G.N., and Reddy, J.N. (1998). Nonlinear transient thermoelastic analysis of functionally graded ceramicmetal plates. Int. J. Solids Struct. 35, pp.4457-4476. DOI:10.1016/S0020-7683(97)00253-9.

[31] Najafizadeh, M.M., Eslami, M.R. (2002). Buckling analysis of circular plates of functionally graded materials under uniform radial compression.Int. J. Mech. Sci. 44, 2479-2493. DOI: 10.1016/S0020-7403(02)00186-8

[32] Merdaci, S., Belmahi, S., Belghoul, H., and Hadj Mostefa, A. (2019). Free Vibration Analysis of Functionally Graded Plates FG with Porosities, (IJERT), 8(3), pp.143-147.

https://www.univusto.dz/site_divers/AJRT/article2/AnalysisofBendingFunctionallyGradedPlateswithPorositiesUsin gHighOrderShear'Theory.pdf

[33] Merdaci, S., (2019). Free Vibration Analysis of Composite Material Plates "Case of a Typical Functionally Graded FG Plates Ceramic/Metal" with Porosities, Nano Hybrids and Composites (NHC), 25, pp.69-83.

DOI: $10.4028 /$ www.scientific.net/NHC.25.69.

[34] Merdaci, S. (2018). Analysis of Bending of Functionally Graded Plates With Porosities Using of High Order Shear Theory, Algerian Journal of Research and Technology AJRT, 2, pp. 54-69. https://www.ijert.org/research/freevibration-analysis-of-functionally-graded-plates-fg-with-porosities IJERTV8IS030098.pdf.

[35] Merdaci, S., Boutaleb, S., Hellal, H., and Benyoucef, S. (2019). Analysis of Static Bending of Plates FGM Using Refined High Order Shear Deformation Theory, J. Build. Mater. Struct. 6(1), pp.32-38.

DOI: $10.5281 /$ zenodo.2609306.

\section{NOMENCLATURE}

$a$ : Length of the plate

$b$ : Width of the plate

$b$ : Total thickness of the plate

$q$ : Intensity of load

$u, v, w$ : Displacement in $\mathrm{x}, \mathrm{y}$ and $\mathrm{z}$ directions, respectively

$u_{0}, v_{0}, w_{0}$ : Mid-plane displacements in $\mathrm{x}, \mathrm{y}$ and $\mathrm{z}$ directions, respectively

$x, y, z$ : Cartesian co-ordinates

$E_{c}$ and $E_{m}$ are the corresponding properties of the ceramic and metal
$V$ : Volume fraction
$P$ : Exponent graded factor
$a$ : Porosity volume fraction

$A_{i j}$ : Rigidity terms in membrane of the plate

$B_{i j}$ : Rigidity terms of coupling the plate

$D_{i j}$ : Rigidity terms of bending the plate

$A_{i j}^{s}$ : Rigidity terms of the plate in shear

$B_{i j}^{s}$ : Rigidity terms of the plate in shear

$D_{i j}^{s}$ : Rigidity terms of the plate in shear

$H_{i j}^{s}$ : Rigidity terms of the plate in shear

$N$ : Normal membrane efforts

$M^{b}:$ Moments of pure bending

$M^{s}$ : Additional bending moment due to transverse shear

$S$ : Pure shearing effort. 
$f(z)$ : Warping function (transverse shear function)

$f^{\prime}(z)$ : The first derivative of the warp function with respect to $\mathrm{Z}$

$\sigma_{x}, \sigma_{y}, \sigma_{z}:$ Normal stresses

$\tau_{x y}, \tau_{y z}, \tau_{y x}:$ Shear stress

$\varepsilon_{x}, \varepsilon_{y}$ : Deformation in the $\mathrm{x}, \mathrm{y}$ and $\mathrm{z}$ direction

$\gamma_{x y}, \gamma_{y z}, \gamma_{y x}:$ Distortion deformation

$\delta u, \delta v, \delta w_{b}, \delta w_{s}$ : Virtual field of displacement

$w_{b}$ : Flexural components

$w_{s}$ Shear components

$m, n$ : Mode numbers.
$\Omega$ : The upper surface.

$Q_{i j}$ : The stiffness coefficients

$i, j:$ Natural numbers.

$[\mathrm{K}]$ : Symmetrical matrix
$\{\Delta\}$ : Vector of generalized displacements
$\{F\}$ : Vector of generalized efforts
$\bar{w}$ : Non-dimensional central deflection
$\bar{\sigma}_{x}, \bar{\sigma}_{y}, \bar{\tau}_{x y}, \bar{\tau}_{x z}, \bar{\tau}_{y z}:$ Non-dimensional stresses
$\bar{z}$ : Coordinate Thickness 